BMJ Open

Sport \&

Exercise

Medicine

\section{Which parameters to use for sleep quality monitoring in team sport athletes? A systematic review and meta- analysis}

João Gustavo Claudino, ${ }^{1,2}$ Tim J Gabbett, ${ }^{3,4}$ Helton de Sá Souza, ${ }^{5}$ Mário Simim, ${ }^{6}$ Peter Fowler, ${ }^{7,8}$ Diego de Alcantara Borba, ${ }^{9}$ Marco Melo, ${ }^{10}$ Altamiro Bottino, ${ }^{10}$ Irineu Loturco, ${ }^{11}$ Vânia D'Almeida, ${ }^{5}$ Alberto Carlos Amadio, ${ }^{1}$ Julio Cerca Serrão, ${ }^{1}$ George P Nassis ${ }^{12}$

\section{ABSTRACT}

Background Sleep quality is an essential component of

J Gabbett T, de Sá Souza H, et al. Which parameters to use for sleep quality monitoring in team sport athletes? A systematic review and meta-analysis. BMJ Open Sport \& Exercise Medicine 2019;5. doi:10.1136/ bmjsem-2018-000475

Accepted 26 November 2018

Check for updates

C) Author(s) (or their employer(s)) 2019. Re-use permitted under CC BY-NC. No commercial re-use. See rights and permissions. Published by BMJ.

For numbered affiliations see end of article.

Correspondence to João Gustavo Claudino; claudinojgo@usp.br athlete's recovery. However, a better understanding of the parameters to adequately quantify sleep quality in team sport athletes is clearly warranted.

Objective To identify which parameters to use for sleep quality monitoring in team sport athletes.

Methods Systematic searches for articles reporting the qualitative markers related to sleep in team sport athletes were conducted in PubMed, Scopus, SPORTDiscus and Web of Science online databases. The systematic review followed the Preferred Reporting Items for Systematic Reviews and Meta-Analyses guidelines. For the metaanalysis, effect sizes with $95 \% \mathrm{Cl}$ were calculated and heterogeneity was assessed using a random-effects model. The coefficient of variation (CV) with $95 \% \mathrm{Cl}$ was also calculated to assess the level of instability of each parameter.

Results In general, 30 measuring instruments were used for monitoring sleep quality. A meta-analysis was undertaken on 15 of these parameters. Four objective parameters inferred by actigraphy had significant results (sleep efficiency with small CV and sleep latency, wake episodes and total wake episode duration with large CV). and scales also had meaningful results (Pittsburgh Sleep Quality Index (sleep efficiency), Likert scale (Hooper), Likert scale (no reference), Liverpool Jet-Lag Questionnaire, Liverpool Jet-Lag Questionnaire (sleep rating) and RESTQ (sleep quality)).

Conclusions These data suggest that sleep efficiency using actigraphy, Pittsburgh Sleep Quality Index, Likert scale, Liverpool Jet-Lag Questionnaire and RESTQ are indicated to monitor sleep quality in team sport athletes. PROSPERO registration number CRD42018083941.

\section{INTRODUCTION}

Good sleep quality is a well-recognised predictor of physical and mental health, wellness and overall vitality. ${ }^{1}$ However, the term 'sleep quality' has been poorly defined yet ubiquitously used by researchers, clinicians Six subjective parameters obtained from questionnaires

\section{What is already known}

- Good sleep quality is important for physical and mental health, wellness and overall vitality.

- Poor sleep quality may lead to accumulation of fatigue, drowsiness and mood changes.

- The term 'sleep quality' has been poorly defined yet ubiquitously used by researchers, clinicians and patients.

- Researchers, clinicians and practitioners have had difficulty to determine the better parameters for monitoring sleep quality.

\section{What are the new findings}

Thirty measuring instruments were used for monitoring sleep quality in team sport athletes.

- The most prevalent ones were (1) actigraphy, (2) Likert rating scale (no reference), (3) Likert rating scale (based on Hooper), (4) Pittsburgh Sleep Quality Index, (5) Epworth Sleepiness Scale and RESTQSport, (6) Liverpool Jet-Lag Questionnaire and Patient-Reported Outcomes Measurement System, and (7) polysomnography.

- Ten sleep quality parameters were identified; four inferred by actigraphy (sleep efficiency, sleep latency, wake episodes and total wake episode duration) and six other quality parameters obtained from questionnaires and scales (including Pittsburgh Sleep Quality Index (sleep efficiency), Likert scale (Hooper), Likert scale (no reference), Liverpool JetLag Questionnaire, Liverpool Jet-Lag Questionnaire (sleep rating) and RESTQ (sleep quality)).

- The more adequate parameters for monitoring sleep quality should have a small to moderate coefficient of variation and a moderate to large effect size.

and patients. ${ }^{2}$ Because of this, the National Sleep Foundation assembled a panel of experts from the sleep community and provide the first report on sleep quality recommendations pointing to these key determinants to be 
followed: sleeping more time while in bed (at least $85 \%$ of the total time), falling asleep in $30 \mathrm{~min}$ or less, waking up no more than once per night, and being awake for 20 min or less after initially falling asleep. ${ }^{1}$ Sleep quality of athletes may be altered due to different factors, among them, the congested competition calendar, low sleep priority in relation to other training demands as well as lack of knowledge regarding the role of sleep in optimising sports performance. ${ }^{3-5}$ In general, athletes are frequently exposed to circadian rhythm desynchronisation (eg, jet lag during international competitions), changes in sleeping habits (eg, hotel sleep, number of athletes per room), late-night matches, and stress and muscle pain due to competition, intense training and travelling. ${ }^{6}$

A poor sleep quality may lead to accumulation of fatigue, drowsiness and changes in mood. ${ }^{7}$ Furthermore, insufficient sleep has been negatively related to physical performance (eg, speed and anaerobic power), neurocognitive function (eg, attention and memory) and physical health (eg, illness and injury risk). ${ }^{378}$ Reduction in sleep quality and quantity may contribute to an imbalance of the autonomic nervous system function, resulting in symptoms of overtraining syndrome and elevation of inflammatory markers and, finally, immune system dysfunction. ${ }^{8}$ Furthermore, differences between the characteristics from individual and team sports can influence the quantity (eg, total sleep time) and quality of sleep (eg, sleep efficiency and sleep latency) of the athletes. ${ }^{48}$ In particular in team sports, it is not uncommon for match or competitions to be held at night to optimise the audience attendance (eg, night football games). From this perspective, it seems reasonable to assume that sleep in team sport athletes depends on many factors, including the type of sport, training demands, age, time of year and team culture. ${ }^{9}$ In addition, the main reasons for sleep disorders in team sports are related to night games, ${ }^{89}$ due to the fact that athletes are often required to travel following the matches, ${ }^{8}$ to the congested fixtures calendar ${ }^{4}$ and to the maladaptation of training in sleep loss. ${ }^{6}$ Furthermore, after night games, sometimes the athletes may use this moment for socialising and drinking with family and friends. ${ }^{6}$ These factors explain why the time course of recovery for both performance and psychophysiological measures is affected after sleep disorders. ${ }^{48}$

The number of studies on sleep involving team sport athletes has considerably increased over the last years, ${ }^{8}$ and three recent reviews have discussed the role of sleep in the recovery of team sport athletes. ${ }^{81011}$ To date, the emphasis has been on monitoring sleep in team sport athletes using different instruments (eg, polysomnography (PSG), actigraphy, questionnaires and scales). The gold standard is PSG; however, the feasibility of the measurement in the field is limited for monitoring sleep in the team sport athletes. Therefore, questionnaires and scales for sleep monitoring are commonly used as they are inexpensive and easy to implement in the field.
Moreover, previous research has indicated good agreement (ie, validity) between some actigraphy measures and PSG, another instrument with easy implementation in the field. ${ }^{6}$ Regardless, all these instruments suggest sleep quality is insufficient in team sport athletes due to non-negotiable factors as competition schedules (eg, late evening) and frequent travel as well as negotiable factors as training times (eg, early morning or late evening) and poor sleep habits (eg, light exposure, electronic device use and caffeine consumption). ${ }^{6}$

Therefore, given the importance of sleep quality parameters in an athlete's recovery process, a better understanding of the contribution of these parameters may be helpful for scientists and practitioners. An understanding of which parameters to use for sleep quality monitoring in team sport athletes warrants investigation. Several questions about sleep quality should be appropriately discussed, one of which would be the instruments used to monitor sleep. Considering the importance of these issues, the purpose of this systematic review and meta-analysis was to identify which parameters to monitor sleep quality in team sport athletes.

\section{METHODS}

\section{Procedure and registration}

The review methodology adopted the Preferred Reporting Items for Systematic Reviews and Meta-Analyses guidelines and was prospectively registered in the PROSPERO database for systematic reviews. The selection process and data extraction methods were completed by three authors (JGC, HdSS and MS). The quality appraisal was completed by two authors (HdSS and MS).

\section{Search strategy}

Four electronic databases (PubMed, Scopus, SPORTDiscus and Web of Science) were systematically searched from inception up to October 2017. The command line ("sleep" OR "sleep quality" OR "sleep quantity" OR "sleep behavior" OR "sleep disturbance" OR "sleep deprivation" OR "circadian rhythm") AND ("team sport" OR "team sports" OR "soccer"' OR "football" OR "rugby" OR "hockey" OR "cricket" OR "futsal" OR "volleyball" OR "basketball" OR "korfball" OR "netball" OR "handball" OR "baseball" OR "softball” OR "lacrosse" OR "curling" OR "polo") was used during the electronic search.

\section{Eligibility criteria and selection process}

Systematic review

Three authors (JGC, HdSS and MS) reviewed and identified the titles and abstracts based on the following inclusion criteria:

1. The study was written in English.

2. The study was published as original research in a peer-reviewed journal as a full-text article.

3. Data were reported specifically for team sport athletes.

4. Study performed during the athlete's sporting career.

5. The participants were competitive athletes (defined as olympic, international, professional, semiprofessional, national, youth elite or division I collegiate). 


\begin{tabular}{|c|c|c|c|c|c|}
\hline \multirow{2}{*}{\multicolumn{2}{|c|}{ Criteria }} & \multirow{3}{*}{$\begin{array}{l}\text { Definition } \\
\text { Study published in peer-reviewed journal }\end{array}$} & \multicolumn{3}{|c|}{ Scoring } \\
\hline & & & \multirow{2}{*}{0} & \multirow{2}{*}{1} & \multirow{2}{*}{2} \\
\hline A & Peer reviewed & & & & \\
\hline B & No of participants & No of participants included in study findings & $<5$ & $6-30$ & $>31$ \\
\hline C & Population defined & Age, gender, sport, time experience were described & No & Partly & Yes \\
\hline D & Experimental design & Experimental design of the study period was described and replicable & No & Partly & Yes \\
\hline $\mathrm{E}$ & Sleep parameters & The sleep parameters were described & No & Yes & - \\
\hline
\end{tabular}

6. Sleep quality parameters were included.

7. The participants had not used chronic medication/ drugs.

\section{Meta-analysis}

Three authors (JGC, HdSS and MS) were asked to review the selected articles for inclusion in the meta-analysis. To meet the inclusion criteria for the meta-analysis, the sleep parameters were required to be measured at baseline and postintervention with the aim of verifying team sport practice effects on sleep quality. Moreover, the parameters analysed were required to be reported in more than one study. If pertinent data were absent, the authors were contacted and the necessary information was requested via email. If the original data were not provided by the authors, the mean and SD were extracted from graphical representation using the tool Ycasd ${ }^{12}$ or estimated from the median, range and sample size. ${ }^{13}$ Sleep parameters were separate in subjective and objective measurements of sleep quality. Subjective parameters were from questionnaires and scales whereas objective parameters were inferred by actigraphy, PSG and other equipment.

\section{Quality assessment}

The quality of all studies was evaluated by two authors (HdSS and MS) using evaluation criteria (table 1) based on a study by Saw et al. ${ }^{14}$ Scores were allocated based on how well each criterion was met, assuming a maximum possible score of 8 (low risk of bias). Studies with a risk of bias score of 4 or less were considered poor, and were excluded. The Kappa agreement ( $\kappa$ ) was used to describe the intensity of agreement between the two reviewers, being interpreted from the scale of magnitude proposed by Altman. ${ }^{15}$

Publication bias was determined for the meta-analysis using an approach where differences in baseline assessments were checked for all intervention groups. Then, the interventions were separated into non-significant $(p>0.05)$ or significant $(p<0.05)$ results to determine the percentage of interventions with non-significant differences (according to other meta-analyses performed previously). ${ }^{1617}$

\section{Statistical analysis}

Heterogeneity of the included studies was evaluated by examining forest plots, CIs and $\mathrm{I}^{2}$. The $\mathrm{I}^{2}$ values of 25,50 and 75 indicate low, moderate and high heterogeneity, respectively. ${ }^{18}$ Random effects were analysed using the DerSimonian and Laird approach. ${ }^{19}$ The meta-analysis was conducted based on the number of sleep quality parameters. Statistical significance was set at $p$ value $\leq 0.05$ and the magnitude of differences for each dependent variable were calculated using Hedges $(\mathrm{g})$ effect size (ES) with $95 \%$ CIs. ${ }^{19}$ The sensitivity of the sleep parameters was assessed using ES (large effect, $>0.80$; moderate effect, $0.20-0.80$; small effect, $<0.20) .{ }^{20}$ The coefficient of variation (CV) (ie, (SD/mean) $\times 100,{ }^{21}$ with $\left.95 \% \mathrm{CI}\right)^{22}$ of each sleep parameter was calculated to interpret its respective level of instability. ${ }^{23} \mathrm{~A}$ scale for the $\mathrm{CV}$ has been suggested with $\mathrm{CV}>30 \%=$ large and CV $<10 \%=$ small. $^{24}$ Variables with a large $\mathrm{CV}$ are less likely (OR) to detect statistically significant differences. ${ }^{25}$ All data were analysed using CMA V.3 trial (Biostat, New Jersey, USA) and Excel 2013 worksheet (Microsoft, Washington, USA) ${ }^{26}$

\section{RESULTS}

The initial search returned 1809 articles (figure 1). After the removal of duplicate articles $(n=900)$, a total of 909 studies were retained for full text screening. Following eligibility assessment, 832 studies were excluded as they did not meet the set inclusion criteria. Thus, 77 studies, published between 1993 and 2017, were included in this systematic review. Fifty-six per cent of articles were published in the last 3 years (for details see online supplementary table 1). ${ }^{927-102}$ In addition, 42 did not meet the meta-analysis criteria. Therefore, 35 studies were included in the meta-analysis. There was good agreement between the two reviewers $(\kappa=0.761,95 \%$ CI $(0.677$ to $0.845) ; \mathrm{p}<0.0001$; agreement percentage $=83 \%)$.

\section{Characteristics of the studies}

The pooled sample size and age were 4083 participants and $23 \pm 4$ years, respectively, with the vast majority $(91 \%)$ composed by men. About half of the sample (47\%) were Soccer players, $16 \%$ Australian Football League players, 12\% Basketball, 9\% Rugby League, 5\% American Football, 5\% Rugby Union, 4\% Ice Hockey, 4\% Netball, 3\% Field Hockey, 3\% Volleyball and 1\% each were Blind Soccer, Cricket, Gaelic Football, Rugby Sevens, Softball, Water Polo, Wheelchair Basketball and Wheelchair Rugby players. The studies were developed in 27 countries around the world with a large majority in Australia (44\%), UK (17\%), USA (13\%) and Qatar (10\%) (for 


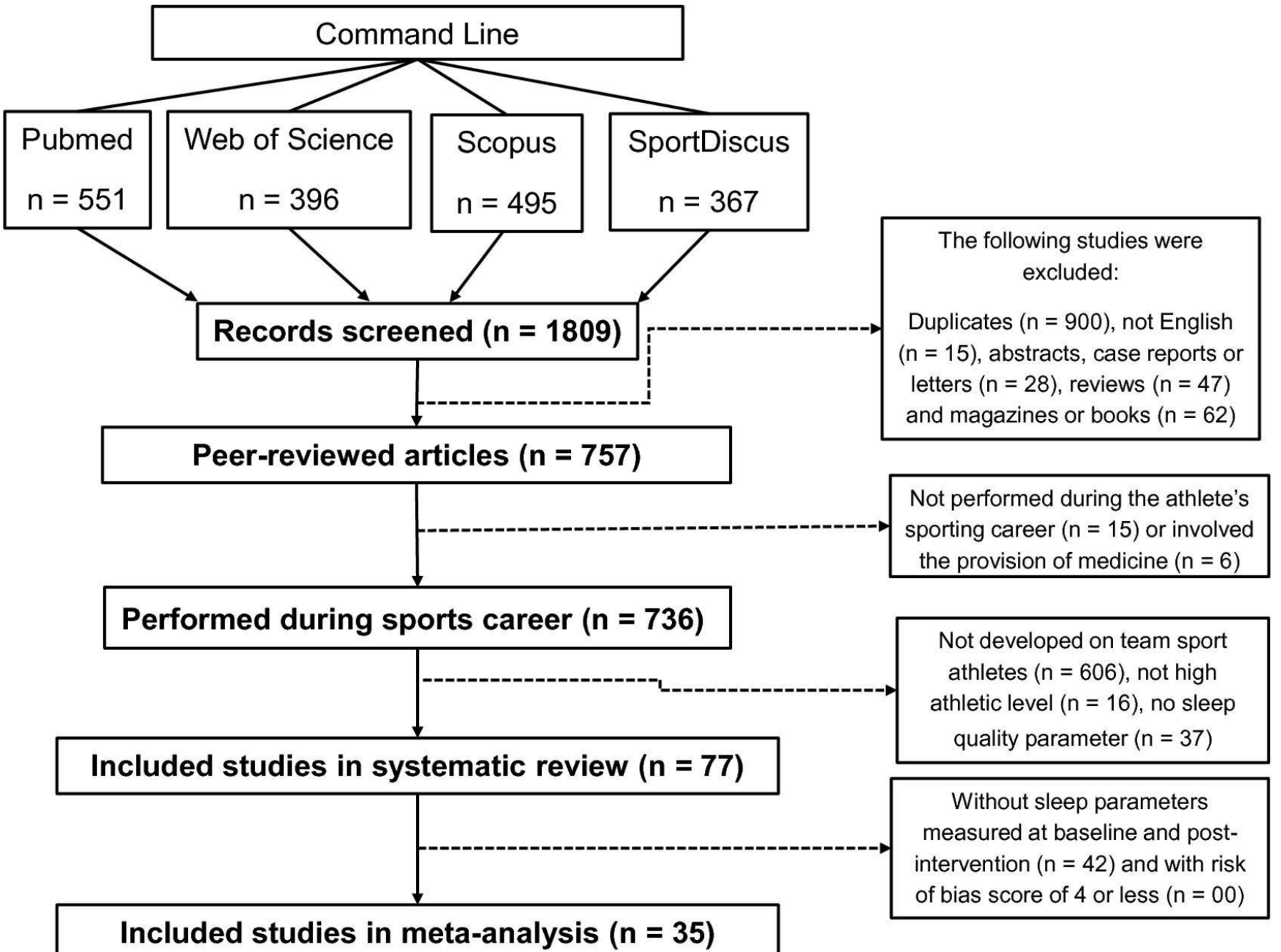

Figure 1 Study selection Preferred Reporting Items for Systematic Reviews and Meta-Analyses flow diagram.

details see online supplementary table 1 ). The pooled duration of the interventions was, on average, 9 weeks (range, 1-60 weeks). Furthermore, the interventions were performed during season (29\%), diagnostic of sleep disorders $(25 \%)$, short and long-haul air travel $(16 \%)$, pre-season (8\%), Ramadan (6\%), evening competition $(5 \%)$, sleep hygiene $(5 \%)$, sleep deprivation $(4 \%)$, red or bright light treatment (3\%) and early evening training $(1 \%)$.

\section{Risk of bias}

All included studies had a low risk of bias, with a score $>4$ (see online supplementary table 2 ). The average bias score for the studies was 7 (range, 5-8). For the included articles in the meta-analysis that reported the $\mathrm{p}$ value, $85 \%$ of the intervention groups resulted in non-significant $(p>0.05)$ differences at baseline assessments (ie, 208 interventions with non-significant differences/244 overall interventions $=85 \%$ ) .

\section{Systematic review findings}

Initially, in order to permit an adequate reading flow, the summary of the 77 studies included in the systematic review are described in online supplementary table 3 . Thirty measurement instruments were used for monitoring sleep quality in team sport athletes with 24 (ie, $80 \%$ ) of them being questionnaires and scales (table 2). The following instruments were the most prevalent: (1) actigraphy with seven different type of devices (32\%); (2) Likert rating scales without references being provided (19\%); (3) Likert rating scale based on Hooper et al ${ }^{103} 104$ (18\%); (4) Pittsburgh Sleep Quality Index (12\%); (5) Epworth Sleepiness Scale and Recovery-Stress Questionnaire for Athletes (RESTQ-Sport) (8\%); (6) Liverpool Jet-Lag Questionnaire and Patient-Reported Outcomes Measurement System (PROMIS) (6\%); (7) PSG with three different type of devices $(5 \%)$. Information on the validity and reliability of the most prevalent instruments listed above were reported in almost $100 \%$ of articles, except for actigraphy (validity $=84 \%$ and reliability $=80 \%$ ) and Likert rating scales without references being provided (validity $=0 \%$ and reliability $=7 \%$ ).

The CV of the sleep quality parameters inferred by actigraphy also was calculated to determine their level of instability (see table 3). Variables with a large CV (ie, 
Table 2 Instruments used for sleep quality monitoring

\begin{tabular}{|c|c|c|c|c|}
\hline \multicolumn{2}{|c|}{ Instruments } & \multirow{2}{*}{$\begin{array}{l}\begin{array}{l}\text { Percentage of } \\
\text { articles }(\%)^{*}\end{array} \\
32(25 \\
\text { articles })\end{array}$} & \multirow{2}{*}{$\begin{array}{l}\text { Validity }(\%) \dagger \\
84 \text { of articles }\end{array}$} & \multirow{2}{*}{$\begin{array}{l}\text { Reliability }(\%) \dagger \\
80 \text { of articles }\end{array}$} \\
\hline 1 & Actigraphy (7 different devices were used) $\ddagger$ & & & \\
\hline 2 & Rating Likert scales (no references were provided) & $\begin{array}{l}19(15 \\
\text { articles) }\end{array}$ & 0 of articles & 7 of articles \\
\hline 3 & Rating Likert scale (based on Hooper and Mackinnon $1995^{103}$ ) & $\begin{array}{l}18(14 \\
\text { articles) }\end{array}$ & 100 of articles & 100 of articles \\
\hline 4 & Pittsburgh Sleep Quality Index (Buysse et al 1989) & 12 (9 articles) & 100 of articles & 100 of articles \\
\hline 5 & Epworth Sleepiness Scale (Johns 1991) & 8 (6 articles) & 100 of articles & 100 of articles \\
\hline 6 & RESTQ-Sport (Kellmann; Kallus 2001) & 8 (6 articles) & 100 of articles & 100 of articles \\
\hline 7 & Liverpool Jet-Lag Questionnaire (Waterhouse et al 2000) & 6 (5 articles) & 100 of articles & 100 of articles \\
\hline 8 & PROMIS (Yu et al 2011) & 6 (5 articles) & 100 of articles & 100 of articles \\
\hline 9 & Polysomnography (3 different devices were used)§ & 5 (4 articles) & Gold standard & Gold standard \\
\hline 10 & Rating Likert scale (based on Kölling et al 2014) & 4 (3 articles) & 100 of articles & 100 of articles \\
\hline 11 & Sleep diary (no reference was provided) & 4 (3 articles) & 0 of articles & 0 of articles \\
\hline 12 & Insomnia Severity Index (Bastien 2001) & 3 (2 articles) & 100 of articles & 100 of articles \\
\hline 13 & Visual Analogue Scale (no reference was provided) & 3 (2 articles) & 0 of articles & 0 of articles \\
\hline 14 & Stanford Sleepiness Scale (Hoddes et al 1972, 1973) & 3 (2 articles) & 100 of articles & 100 of articles \\
\hline 15 & Basic Nordic Sleep Questionnaire (Partinen; Gislason 1995) & 1 (1 article) & 0 of articles & 0 of articles \\
\hline 16 & Competitive Sports and Sleep Questionnaire (Erlacher et al 2011) & 1 (1 article) & 0 of articles & 0 of articles \\
\hline 17 & Karolinska Sleepiness Scale (Akerstedt 1990) & 1 (1 article) & 0 of articles & 0 of articles \\
\hline 18 & Peripheral Arterial Tonometry (PAT, WatchPAT-200; Itamar Medical) & 1 (1 article) & 100 of articles & 100 of articles \\
\hline 19 & Photoplethysmography (Morpheus Ox; WideMed) & 1 (1 article) & 100 of articles & 100 of articles \\
\hline 20 & Portable sleep apnoea monitoring (Apnealink) & 1 (1 article) & 100 of articles & 100 of articles \\
\hline 21 & Question (no reference was provided) & 1 (1 article) & 0 of articles & 0 of articles \\
\hline 22 & Rating Likert scale (based on Brandt et al 2014) & 1 (1 article) & 100 of articles & 100 of articles \\
\hline 23 & Rating Likert scale (based on Carney et al $2012^{117}$ ) & 1 (1 article) & 0 of articles & 0 of articles \\
\hline 24 & Rating Likert scale (based on Rains et al 2012) & 1 (1 article) & 0 of articles & 0 of articles \\
\hline 25 & $\begin{array}{l}\text { Self-Assessment Questionnaire of Sleep and Awakening quality (Salute et al } \\
\text { 1987) }\end{array}$ & 1 (1 article) & 100 of articles & 100 of articles \\
\hline 26 & Sleep-Apnea Screening Questionnaire (no reference was provided) & 1 (1 article) & 0 of articles & 0 of articles \\
\hline 27 & Self-report diaries (based on Sargent et al 2001) & 1 (1 article) & 0 of articles & 0 of articles \\
\hline 28 & Sleep-EEG (Fp2-A1; Somnowatch) & 1 (1 article) & 0 of articles & 0 of articles \\
\hline 29 & $\begin{array}{l}\text { Subjective sleep questionnaire: Regman (German Federal Institute of Sport } \\
\text { Science) }\end{array}$ & 1 (1 article) & 100 of articles & 100 of articles \\
\hline 30 & Total Quality Recovery action (TQRact) (Kenttä; Hassmén 1998) & 1 (1 article) & 100 of articles & 100 of articles \\
\hline
\end{tabular}

*Percentage of total articles (number of articles).

†Percentage of the articles that present information on validity and reliability of measuring instruments or reference

‡Philips Respironics $(n=10)$; Fatigue Science $(n=4)$; Actigraph $(n=4)$; Ambulatory Monitoring $(n=3)$; Cambridge Neurotechnology $(n$ $=3)$; SenseWear $(n=2)$; Zeo $(n=1)$.

§Compumedics ( $n=1)$; Medcare Embla/Somnologica System $(n=1)$; Randersacker $(n=1)$.

$\mathrm{CV}>30 \%=$ large) are less likely (OR) to detect statistically significant differences during repetitive measurement. ${ }^{25}$ The definition and procedures used to measure objective parameters inferred by actigraphy are presented in table 4 .

\section{Meta-analysis findings}

Meta-analyses were performed on the 15 sleep quality parameters (figure 2). Five objective parameters were inferred by actigraphy: (1) sleep efficiency (ES=0.46 (0.32 to 0.61$), \mathrm{p}<0.01 ; \mathrm{I}^{2}=59.3, \mathrm{p}<0.01$ ), (2) sleep latency ( $\mathrm{ES}=0.34$ (0.20 to 0.47$), \mathrm{p}<0.01 ; \mathrm{I}^{2}=00.0, \mathrm{p}=0.84$ ), (3) time awake ( $\mathrm{ES}=0.28$ ( -0.01 to 0.57 ), $\mathrm{p}=0.06 ; \mathrm{I}^{2}=30.4, \mathrm{p}=0.22$ ), (4) wake episodes ( $\mathrm{ES}=0.55$ (0.35 to 0.75$), \mathrm{p}<0.01$; $\left.\mathrm{I}^{2}=43.8, \mathrm{p}<0.01\right)$ and $(5)$ total wake episodes duration ( $\mathrm{ES}=0.58$ (0.39 to 0.77$), \mathrm{p}<0.01 ; \mathrm{I}^{2}=12.4, \mathrm{p}=0.03$ ). Ten subjective parameters were obtained from questionnaires 
Table 3 Coefficient of variation (CV) of the objective parameters inferred by actigraphy

\begin{tabular}{|c|c|c|}
\hline \multicolumn{2}{|c|}{ Objective parameters } & \multirow{2}{*}{$\frac{\text { CV (95\% Cl) }}{2 \text { (2 to } 2)}$} \\
\hline 1 & Mean activity score, $\min ^{*}$ & \\
\hline 2 & Sleep efficiency, \% & 7 (6 to 8$)$ \\
\hline 3 & Time asleep, $\min ^{*}$ & 10 (7 to 14$)$ \\
\hline 4 & Actual sleep, \%* & 11 (10 to 12$)$ \\
\hline 5 & Moving time, \%* & 34 (31 to 37$)$ \\
\hline 6 & Wake variance, $\min ^{\star}$ & 41 (39 to 42$)$ \\
\hline 7 & Time awake, min & 41 (26 to 56$)$ \\
\hline 8 & Sleep onset variance, $\min ^{*}$ & 45 (35 to 55) \\
\hline 9 & Wake episodes, $n$ & 58 (51 to 64$)$ \\
\hline 10 & Total wake episode duration, min & 74 (66 to 82$)$ \\
\hline 11 & Sleep latency, min & 83 (75 to 90$)$ \\
\hline 12 & Variance from mean bed time, min $^{*}$ & 679 (157 to 1200$)$ \\
\hline
\end{tabular}

*This variable was used in just one study.

and scales: (1) Pittsburgh Sleep Quality Index (PSQI) $\left(\mathrm{ES}=0.34(-0.03\right.$ to 0.71$\left.), \mathrm{p}=0.07 ; \mathrm{I}^{2}=00.0, \mathrm{p}=0.70\right),(2)$ PSQI-sleep efficiency (PSQI_efficiency) (ES=0.57 (0.08 to 1.07 ), $\left.\mathrm{p}=0.02 ; \mathrm{I}^{2}=00.0, \mathrm{p}=0.43\right)$, (3) PSQI-sleep latency (PSQI_latency) ( $\mathrm{ES}=0.82(-0.15$ to 1.78$), \mathrm{p}=0.10$; $\mathrm{I}^{2}=71.8, \mathrm{p}=0.03$ ), (4) Epworth Sleepiness Scale (ESS) $\left(\mathrm{ES}=0.86(-0.22\right.$ to 1.95$\left.), \mathrm{p}=0.12 ; \mathrm{I}^{2}=82.2, \mathrm{p}<0.01\right),(5)$ Likert scale (based on Hooper) (ES=0.55 (0.23 to 0.87), $\mathrm{p}<0.01 ; \mathrm{I}^{2}=52.0, \mathrm{p}=0.01$ ), (6) Likert scale (no reference) ( $\mathrm{ES}=0.66$ (0.44 to 0.89), $\left.\mathrm{p}=0.00 ; \mathrm{I}^{2}=31.6, \mathrm{p}=0.12\right)$, (7) Liverpool Jet-Lag Questionnaire (LJLQ) $(\mathrm{ES}=0.93(0.42$ to 1.45$\left.), \mathrm{p}<0.01 ; \mathrm{I}^{2}=67.6, \mathrm{p}<0.01\right)$, (8) Liverpool Jet-Lag Questionnaire-Sleep rating (LJLQ_sleep) (ES=0.63 (0.32 to 0.94$), p<0.01 ; \mathrm{I}^{2}=53.3, \mathrm{p}=0.02$ ), (9) RESTQ (Sleep quality) ( $\mathrm{ES}=0.56$ (0.25 to 0.87$), \mathrm{p}<0.01 ; \mathrm{I}^{2}=52.5, \mathrm{p}=0.04$, (10) Visual Analogue Scale-no reference (ES=0.20 $(-0.09$ to 0.48$\left.), \mathrm{p}=0.18 ; \mathrm{I}^{2}=00.0, \mathrm{p}=1.00\right)$.

\section{DISCUSSION}

In this study, we sought to better understand the sensitivity, level of instability, reliability and efficacy of tools for monitoring sleep quality in team sport athletes. In this sense, we can understand sleep quality as a variable of complex definition and diagnosis which depends directly on some parameters related to sleep architecture such as sleep efficiency, latency and wakefulness duration ${ }^{105} 106$ as well as indirect measures such as perception of sleep quality and level of sleepiness. ${ }^{107} 108$ A more comprehensive understanding of which parameters can adequately indicate sleep quality in team sport athletes has yet to be reported in the literature. In general, 30 measuring instruments were used for sleep quality monitoring (for details see table 2). A meta-analysis was undertaken concerning 15 of these parameters. Four objective parameters inferred by actigraphy had significant results with sleep efficiency presenting a moderate ES with small CV. In addition, three parameters (sleep latency, wake episodes and total wake duration) also showed moderate ES but with large CV. Six other subjective parameters obtained from questionnaires and scales had significant results with moderate and large ES: PSQI_efficiency, Likert scale (based on Hooper), Likert scale (no reference), LJLQ, LJLQ_sleep and RESTQ (Sleep quality).

For the most prevalent instruments, some advantages and disadvantages deserve discussion. Actigraphy was the most commonly used method from practitioners and sports scientists, probably due to the ease of its field application and their high validity and reliability. This assessment uses an accelerometer, similar to a wrist watch which continuously monitors body movements and provides information on long-term sleep-wake patterns in athletes' natural environment. ${ }^{83}$ Additionally, actigraphy in combination with sleep diaries has been useful in tracking sleep and ensuring adequate time in bed. ${ }^{6}$ One of the limitations of activity monitors is that sitting for prolonged periods (eg, on a plane) can be mistakenly scored as sleep by the software algorithm. This highlights the importance of using them in combination with a sleep diary. However, this recommendation was not followed by all studies included in this review (for details see table 4). Actigraphy is particularly suitable for the assessment of sleep schedule disorders because it enables continuous monitoring for extended periods of time. ${ }^{109}$ Another potential application of actigraphy is monitoring sleep during naturalistic studies of sleep restriction and other imposed demands for athletes (training, travel and competition days). ${ }^{110}$ It has been shown that actigraphy can validate the compliance of athletes during a sleep restriction/extension home study. ${ }^{111112}$ However, we must consider that the main limitations of this method are (1) it only measures activity and rest; (2) it does not provide data on sleep stages, breathing or specific behaviours; and (3) artefacts of movements as induced movements, device removal and motionless wakefulness are threats to validity. In addition, the devices identified in the present study, sold commercially, contain different algorithms, making it difficult to standardise the measured parameters. Specific software uses algorithms to process data based on one of three sleep-wake threshold settings (ie, low, medium or high) for processing actigraphy data. Study reported that a medium sleep-wake threshold (activity counts above 40) should be used to process sleep data for team sport male athletes. ${ }^{83}$ Therefore, there is a need for a consensus to define the parameters (for details see table 4) and the algorithms used to calculate them.

Based on the actigraphy findings to date, sleep efficiency is recommended for monitoring sleep quality due to its small level of instability (ie, $\mathrm{CV}<10 \%$ ) and moderate effect size. On the other hand, the remaining parameters had a large CV (ie, CV >30\%) for sleep latency, wake episodes and total wake episode duration presenting a moderate ES. However, the use of these variables would seem problematic in tracking sleep quality. A large CV makes it difficult to detect statistical differences between distinct moments (eg, pre, 


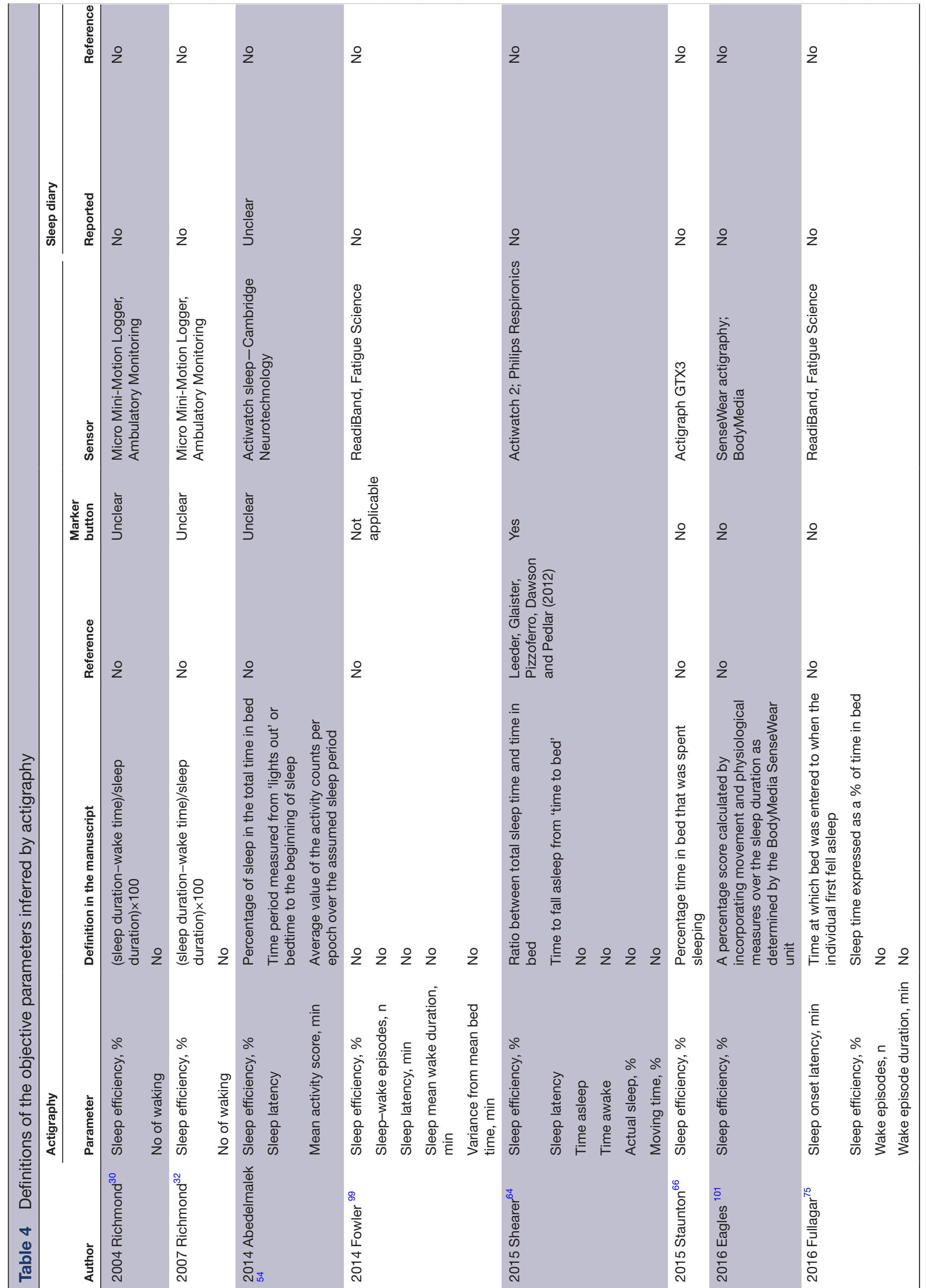




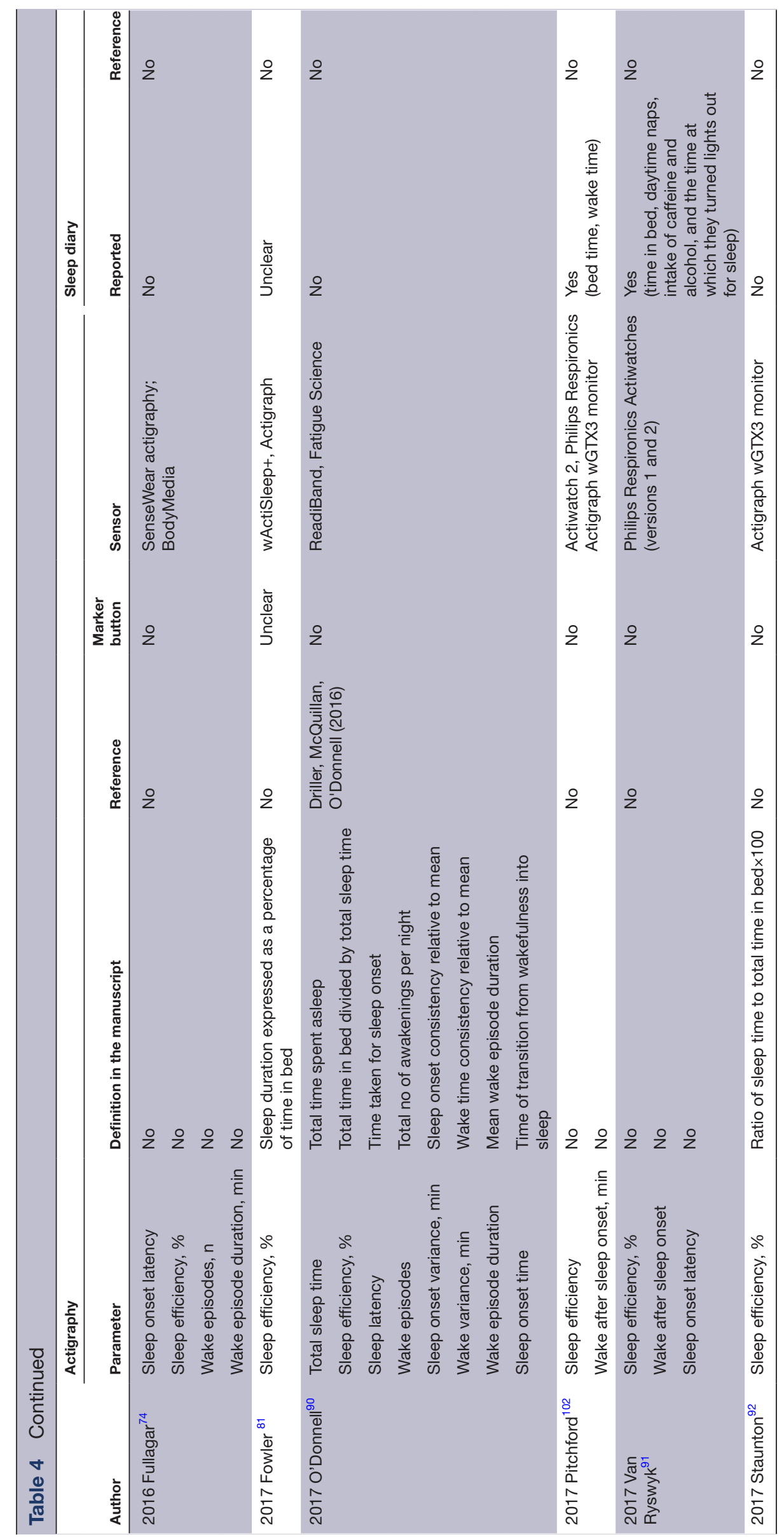




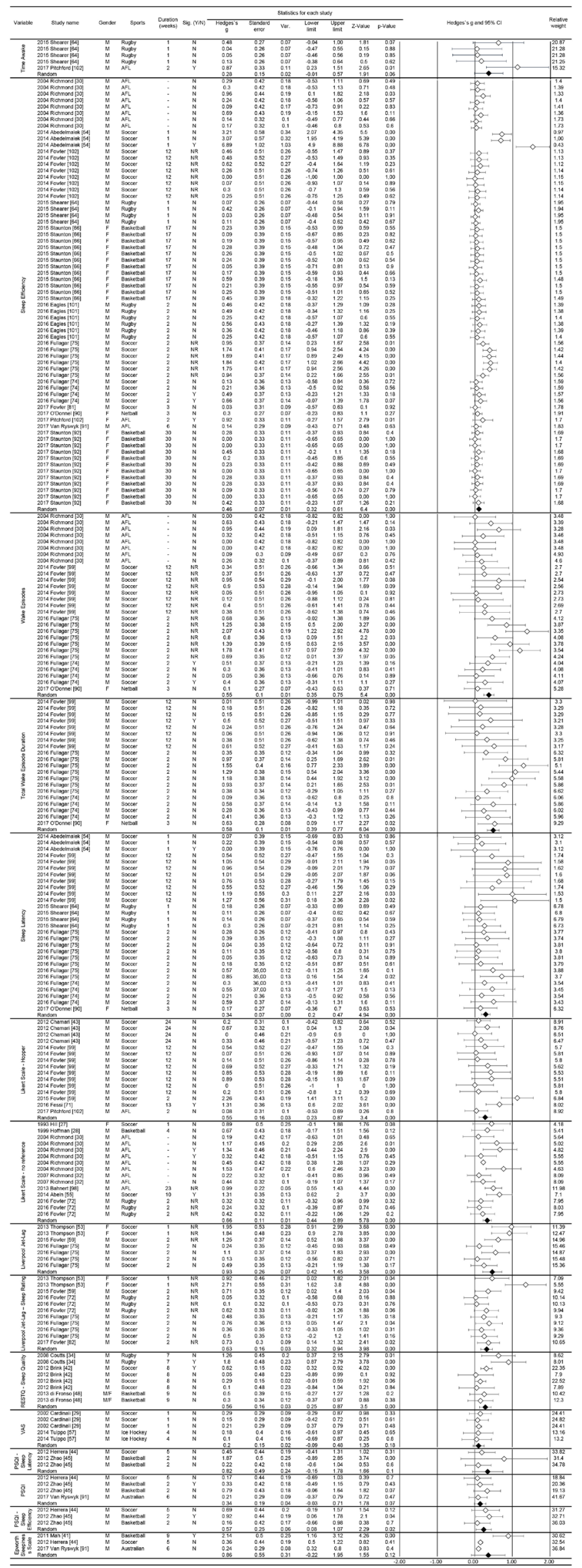

Figure 2 Meta-analysis of short-term intervention studies. 
mid, post) and intervention groups, unless these differences are also very large. ${ }^{25}$ In practice, this means that when using any of these parameters with large CV to monitor sleep quality, the ES should be large in order to be in a position to identify real variations. When they sought to understand the impact of the games played at night by team sport athletes, researchers found significant differences in sleep efficiency, but not in sleep latency and wake episodes. ${ }^{113}$ Furthermore, the results of a recent systematic review and meta-analysis on the effects of training and competition on the sleep of elite athletes are in agreement with our findings. The former study found that the sleep quality, measured by sleep efficiency, was lower $(3 \%-4 \%)$ the night of night competition compared with previous nights. ${ }^{114}$ Concerning sleep efficiency, there is inconsistency in operationally defining as other sleep parameters what creates confusion with regard to the conceptualisation and use of the construct by researchers and clinicians (for details see table 4). The source of the inconsistency are the number of equations used to calculate it. Therefore, a proposed equation to minimise error sources uses the ratio of total sleep time (TST) to duration of the sleep episode (DSE). Considering that DSE is defined as sleep onset latency+TST+time awake after initial sleep onset but before the final awakening+time attempting to sleep after final awakening. The proposed formula for sleep efficiency would be sleep efficiency=TST $/$ DSE $(\times 100)$. TST and DSE can be easily calculated using standard sleep diary entries along with one item from the Expanded Consensus Sleep Diary. ${ }^{115}$ However, it still needs to be verified for the application with actigraphy.

Questionnaires and diaries are user-friendly instruments, have low cost and can measure a wide range of sleep parameters in several contexts. ${ }^{116}$ Sleep diary data may be more accurate for the assessment of some sleep parameters than questionnaires. ${ }^{117}$ Whereas the correlation between subjective and objective measures of quality is modest, subjective reports can provide unique and relevant information. Additionally, diaries can provide information on sleep schedule, night awakenings and related topics. ${ }^{117}$ Many studies have developed tailored questionnaires that preclude comparisons between studies and populations. ${ }^{116}$ However, some questionnaires have been validated and established in the field. For instance, the PSQI and ESS are validated and established questionnaires for assessing sleep problems in the general population, but not in athletes. On the other hand, there is the Athlete Sleep Screening Questionnaire proposed by Samuels et al ${ }^{16}$ that contains a subjective, self-report, sleep-screening questionnaire for elite athletes. These factors may have contributed to the different findings of the present study regarding the sensitivity level of these instruments. Considering that a large majority (ie, 24 instruments, $80 \%$ ) used to monitor the sleep quality were obtained from questionnaires and scales, significant results for sensitivity were only found in $25 \%$ of these instruments in this meta-analysis.
PSG is considered the gold standard for sleep assessment, based on laboratory or ambulatory monitoring, ${ }^{118119}$ as it provides detailed information on sleep architecture and clinical diagnosis. ${ }^{120}$ In this review, we present evidence that PSG can be useful for objective assessment of daytime sleepiness (eg, multiple sleep latency test, maintenance of wakefulness test) (online supplementary table 3). On the other hand, this method is expensive and usually only one or two nights of monitoring may be afforded. It is necessary to consider that PSG can generate discomfort due to the amount of cables needed, and eventually change the sleeping pattern. Due to its associated discomfort, it is not the preferred method from the sleep pattern of high-performance athletes. This fact hinders its use in most field sports science studies ${ }^{83118}$ and explains why there is no study included in this review that have performed pre-evaluations and post-evaluations using PSG. Considering the difficulty of using PSG, many researchers have used indirect methods to evaluate the sleep of athletes and one of the most used evaluations is the actigraphy. This instrument is generally a good choice for those interested in documenting sleep for extended periods of time in the sporting-specific environment due to the ease of application in athletes. Usually associated with actigraphy, some questionnaires and specific scales for sleep investigation are used, perhaps with the intention of complementing the information extracted from the actogram.

Three recent reviews have discussed the role of sleep in the recovery of team sport athletes. ${ }^{81011}$ These reviews suggested that the physiological and psychological processes that occur during sleep are considered critical to optimal recovery ${ }^{10}{ }^{11}$; the detrimental effects of sleep disturbance on postmatch fatigue mechanisms include retardation of muscle glycogen resynthesis, delayed recovery from match-induced muscle damage and/or impairment of muscle repair, impaired cognitive function and increased mental fatigue. ${ }^{10}$ Moreover, sleep hygiene strategies can be used to reduce sleep disruption following night matches and during recovery days to promote restorative sleep. ${ }^{11}$ As presented, the recovery and performance of the athlete are associated with good quality and quantity of sleep, but it is modulated by individuals' characteristics, such as sleep habits, diurnal preferences (chronotype) and daily need for sleep. ${ }^{119}$ Despite having a relatively standardised ideal sleep amount of time (ie, $7-8 \mathrm{~h} /$ day) for most of the population, many individuals have different needs for hours of sleep per night. ${ }^{120}$ Individuals are classified according to the duration of sleep as short or long sleepers. ${ }^{121} 122$ Short sleepers may present good sleep quality perception and recovery status with few hours of sleep, while long sleepers need nine or more hours of sleep to feel recovered or rested. ${ }^{121} 122$

The preference for bedtime and wake time may also be relevant for a good quality of sleep assessments. The chronotype characteristics present three main classifications: (1) 'evening types', who have the habit of dragging 
the beginning of sleep and the time to wake up, that is, to sleep and wake up later; (2) 'morning types', which have the opposite behaviour, they tend to sleep in the first hours of the night and wake up in the early hours of the morning; whereas the (3) 'indifferent types' do not present any of the characteristics of these two chronotypes, thus they adapt more easily to circadian alterations of the wake-sleep cycle. ${ }^{123} 124$

Some limitations of the present study are the inability to access the subjects' chronotype when quantifying the efficiency of the evaluated parameters. Another possible limitation is that the included studies did not report the causes of the wake episodes (eg, if it was for urination, pain or other discomfort, hunger, thirst, etc). Thus, it is important that the characteristics of the subjects are also taken into account in the search for the best strategy for monitoring sleep quality. Furthermore, we recognise the importance of the sleep quantity for the recovery process, but it was not the focus of this review.

Caution and attention is needed on the part of coaches and researchers when choosing parameters to measure and monitor sleep quality in team sport athletes. In addition to the statistical issues (eg, sensitivity, level of instability, reliability), the advantages and disadvantages of each of the sleep monitoring methods, evaluation logistics and sports modality should be taken into account.

\section{CONCLUSIONS}

Our results show that sleep efficiency should be measured to monitor sleep quality by actigraphy in team sport athletes. Moreover, the PSQI (sleep efficiency), Likert scale (based on Hooper and no reference), Liverpool Jet-Lag Questionnaire, Liverpool Jet-Lag Questionnaire (sleep rating) and RESTQ (sleep quality) may also be used in this regard. For the remaining parameters, more studies are needed to verify their efficacy. A consensus regarding (1) the definition of parameters inferred by actigraphy, (2) uniformity in the algorithms used to calculate sleep quality and (3) validation of sleep questionnaires with competitive athletes are warranted.

\footnotetext{
Author affiliations

${ }^{1}$ School of Physical Education and Sport-Laboratory of Biomechanics, University of São Paulo, São Paulo, Brazil

${ }^{2}$ LOAD CONTROL, Contagem, Brazil

${ }^{3}$ Gabbett Performance Solutions, Brisbane, Australia

${ }^{4}$ Institute for Resilient Regions, University of Southern Queensland, Ipswich, Brisbane, Australia

${ }^{5}$ Department of Psychobiology, Universidade Federal de São Paulo—Escola Paulista de Medicina, São Paulo, Brazil

${ }^{6}$ Institute of Physical Education and Sports, Universidade Federal do Ceará, Ceará, Brazil

${ }^{7}$ Aspetar Orthopaedic and Sports Medicine Hospital, Doha, Qatar

${ }^{8}$ Queensland University of Technology, Queensland, Brisbane, Australia

${ }^{9}$ Department of Human Movement Sciences, Universidade do Estado de Minas

Gerais, Ibirité, Brazil

${ }^{10}$ Department of Physiology, São Paulo Futebol Clube, São Paulo, Brazil

${ }^{11}$ NAR—Nucleus of High Performance in Sport, São Paulo, Brazil

${ }^{12}$ Independent Researcher, Athens, Greece
}

Contributors PF, DdAB, MM, AB, IL and VDA analysed data and wrote the manuscript. JGC, TJG, HdSS, MS, ACA, JCS and GPN designed the study, collected and analysed the data, and critically reviewed the manuscript.

Funding The authors have not declared a specific grant for this research from any funding agency in the public, commercial or not-for-profit sectors.

Competing interests None declared.

Patient consent Not required.

Open access This is an open access article distributed in accordance with the Creative Commons Attribution Non Commercial (CC BY-NC 4.0) license, which permits others to distribute, remix, adapt, build upon this work non-commercially, and license their derivative works on different terms, provided the original work is properly cited, appropriate credit is given, any changes made indicated, and the use is non-commercial. See: http://creativecommons.org/licenses/by-nc/4.0/.

\section{REFERENCES}

1. Ohayon M, Wickwire EM, Hirshkowitz M, et al. National Sleep Foundation's sleep quality recommendations: first report. Sleep Health 2017;3:6-19.

2. Harvey AG, Stinson K, Whitaker KL, et al. The subjective meaning of sleep quality: a comparison of individuals with and without insomnia. Sleep 2008;31:383-93.

3. Simpson NS, Gibbs EL, Matheson GO. Optimizing sleep to maximize performance: implications and recommendations for elite athletes. Scand J Med Sci Sports 2017;27:266-74.

4. Gupta L, Morgan K, Gilchrist S. Does elite sport degrade sleep quality? A systematic review. Sports Med 2017;47:1317-33.

5. Marshall GJG, Turner AN. The importance of sleep for athletic performance. Strength Cond J 2016;38:61-7.

6. Kryger M, Roth T, Dement WC. Principles and practice of sleep medicine. Sixth edn. Elsevier, 2017.

7. Chennaoui M, Arnal PJ, Sauvet F, et al. Sleep and exercise: a reciprocal issue? Sleep Med Rev 2015;20:59-72.

8. Fullagar HHK, Duffield R, Skorski S, et al. Sleep and recovery in team sport: current sleep-related issues facing professional teamsport athletes. Int J Sports Physiol Perform 2015;10:950-7.

9. Lastella M, Roach GD, Halson SL, et al. Sleep/wake behaviours of elite athletes from individual and team sports. Eur J Sport Sci 2015;15:94-100.

10. Nédélec M, Halson S, Delecroix B, et al. Sleep hygiene and recovery strategies in elite soccer players. Sports Med 2015;45:1547-59.

11. Nédélec M, Halson S, Abaidia A-E, et al. Stress, sleep and recovery in elite soccer: a critical review of the literature. Sports Med 2015;45:1387-400.

12. Gross A, Schirm S, Scholz M. Ycasd-a tool for capturing and scaling data from graphical representations. BMC Bioinformatics 2014;15:219.

13. Hozo SP, Djulbegovic B, Hozo I. Estimating the mean and variance from the median, range, and the size of a sample. BMC Med Res Methodol 2005;5:13.

14. Saw AE, Main LC, Gastin PB. Monitoring the athlete training response: subjective self-reported measures trump commonly used objective measures: a systematic review. Br J Sports Med 2016;50:281-91.

15. Altman DG. Practical statistics for medical research. New York: Chapman and Hall/CRC, 1990.

16. Claudino JG, Gabbett TJ, Bourgeois F, et al. Crossfit overview: systematic review and meta-analysis. Sports Med Open 2018;4:11.

17. Claudino JG, Cronin J, Mezêncio B, et al. The countermovement jump to monitor neuromuscular status: a meta-analysis. J Sci Med Sport 2017;20:397-402.

18. Higgins JP, Thompson SG, Deeks JJ, et al. Measuring inconsistency in meta-analyses. BMJ 2003;327:557-60.

19. DerSimonian R, Laird N. Meta-analysis in clinical trials. Control Clin Trials 1986;7:177-88.

20. Cohen J. The concepts of power analysis. In: Statistical power analysis for the behavioral sciences. Academic Press, 1977: 1-17.

21. Lewontin RC. On the measurement of relative variability. Syst Zool 1966;15:141-2.

22. Hopkins WG, Hawley JA, Burke LM. Design and analysis of research on sport performance enhancement. Med Sci Sports Exerc 1999;31:472-85.

23. Sokal RR, Braumann CA. Significance tests for coefficients of variation and variability profiles. Syst Zoo 1980;29:50-66.

24. Lande R. On comparing coefficients of variation. Systematic Zoology 1977;26:214-7. 
25. Kraufvelin P. Model ecosystem replicability challenged by the "soft" reality of a hard bottom mesocosm. J Exp Mar Biol Ecol 1998;222-247-67.

26. Neyeloff JL, Fuchs SC, Moreira LB. Meta-analyses and Forest plots using a microsoft excel spreadsheet: step-by-step guide focusing on descriptive data analysis. BMC Res Notes 2012;5:52

27. Hill DW, Hill CM, Fields KL, et al. Effects of jet lag on factors related to sport performance. Can J Appl Physiol 1993;18:91-103.

28. Hoffman JR, Epstein S, Yarom Y. Hormonal and biochemical changes in elite basketball players during a 4-week training camp. J Strength Cond Res 1999;13:280-5.

29. Cardinali DP, Bortman GP, Liotta G, et al. A multifactorial approach employing melatonin to accelerate resynchronization of sleep-wake cycle after a 12 time-zone westerly transmeridian flight in elite soccer athletes. J Pineal Res 2002;32:41-6.

30. Richmond L, Dawson B, Hillman DR, et al. The effect of interstate travel on sleep patterns of elite Australian Rules footballers. J Sci Med Sport 2004;7:186-96.

31. Polman R, Nicholls AR, Cohen J, et al. The influence of game location and outcome on behaviour and mood states among professional rugby league players. J Sports Sci 2007:25:1491-500.

32. Richmond LK, Dawson B, Stewart G, et al. The effect of interstate travel on the sleep patterns and performance of elite Australian Rules footballers. J Sci Med Sport 2007;10:252-8.

33. Zerguini $Y$, Kirkendall D, Junge A, et al. Impact of Ramadan on physical performance in professional soccer players. $\mathrm{Br} J$ Sports Med 2007;41:398-400.

34. Coutts AJ, Reaburn P. Monitoring changes in rugby league players perceived stress and recovery during intensified training. Percept Mot Skills 2008;106:904-16.

35. Leiper JB, Junge A, Maughan RJ, et al. Alteration of subjective feelings in football players undertaking their usual training and match schedule during the Ramadan fast. $J$ Sports Sci 2008;26:S55-S69.

36. Brand S, Beck J, Gerber M, et al. 'Football is good for your sleep': favorable sleep patterns and psychological functioning of adolescent male intense football players compared to controls. $J$ Health Psychol 2009;14:1144-55.

37. Wilson $D$, Drust $B$, Reilly $T$. Is diurnal lifestyle altered during Ramadan in professional Muslim athletes? Biol Rhythm Res 2009;40:385-97.

38. Brand S, Beck J, Gerber M, et al. Evidence of favorable sleep-EEG patterns in adolescent male vigorous football players compared to controls. World J Biol Psychiatry 2010;11:465-75.

39. Killen NM, Gabbett TJ, Jenkins DG. Training loads and incidence of injury during the preseason in professional rugby league players. $J$ Strength Cond Res 2010;24:2079-84.

40. Rice TB, Dunn RE, Lincoln AE, et al. Sleep-disordered breathing in the national football league. Sleep 2010;33:819-24.

41. Mah CD, Mah KE, Kezirian EJ, et al. The effects of sleep extension on the athletic performance of collegiate basketball players. Sleep 2011;34:943-50

42. Brink MS, Visscher C, Coutts AJ, et al. Changes in perceived stress and recovery in overreached young elite soccer players. Scand $J$ Med Sci Sports 2012;22:285-92.

43. Chamari K, Haddad M, Wong DP, et al. Injury rates in professional soccer players during Ramadan. J Sports Sci 2012;30:S93-S102.

44. Herrera CP. Total sleep time in Muslim football players is reduced during Ramadan: a pilot study on the standardized assessment of subjective sleep-wake patterns in athletes. J Sports Sci 2012;30:S85-S91.

45. Zhao J, Tian Y, Nie J, et al. Red light and the sleep quality and endurance performance of Chinese female basketball players. $J$ Athl Train 2012;47:673-8.

46. Beaven CM, Cook C, Gray D, et al. Electrostimulation's enhancement of recovery during a rugby preseason. Int J Sports Physiol Perform 2013;8:92-8.

47. Buchheit M, Racinais S, Bilsborough JC, et al. Monitoring fitness, fatigue and running performance during a pre-season training camp in elite football players. J Sci Med Sport 2013;16:550-5.

48. di Fronso S, Nakamura FY, Bortoli L, et al. Stress and recovery balance in amateur basketball players: differences by gender and preparation phase. Int J Sports Physiol Perform 2013;8:618-22.

49. Gastin PB, Meyer D, Robinson D. Perceptions of wellness to monitor adaptive responses to training and competition in elite australian football. J Strength Cond Res 2013;27:2518-26.

50. Haddad M, Chaouachi A, Wong DP, et al. Influence of fatigue, stress, muscle soreness and sleep on perceived exertion during submaximal effort. Physiol Behav 2013;119:185-9.
51. McNamara DJ, Gabbett TJ, Naughton G, et al. Training and competition workloads and fatigue responses of elite junior cricket players. Int J Sports Physiol Perform 2013;8:517-26.

52. Roach GD, Schmidt WF, Aughey RJ, et al. The sleep of elite athletes at sea level and high altitude: a comparison of sea-leve natives and high-altitude natives (ISA3600). Br J Sports Med 2013;47:1114-20.

53. Thompson A, Batterham AM, Jones $\mathrm{H}$, et al. The practicality and effectiveness of supplementary bright light for reducing jet-lag in elite female athletes. Int J Sports Med 2013;34:582-9.

54. Abedelmalek S, Boussetta N, Chtourou H. Effect of partial sleep deprivation and racial variation on short-term maximal performance. Biol Rhythm Res 2014;45:699-708.

55. Abeln V, Kleinert J, Strüder HK, et al. Brainwave entrainment for better sleep and post-sleep state of young elite soccer players-a pilot study. Eur J Sport Sci 2014;14:393-402.

56. Robey E, Dawson B, Halson S, et al. Sleep quantity and quality in elite youth soccer players: a pilot study. Eur J Sport Sci 2014; $14: 410-7$.

57. Tulppo MP, Jurvelin H, Roivainen E, et al. Effects of bright light treatment on psychomotor speed in athletes. Front Physiol 2014;5:184

58. Buchheit M, Morgan W, Wallace J, et al. Physiological, psychometric, and performance effects of the Christmas break in Australian football. Int J Sports Physiol Perform 2015;10:120-3.

59. Fowler P, Duffield R, Howle K, et al. Effects of northbound long-haul international air travel on sleep quantity and subjective jet lag and wellness in professional Australian soccer players. Int J Sports Physiol Perform 2015;10:648-54.

60. Juliff LE, Halson SL, Peiffer JJ. Understanding sleep disturbance in athletes prior to important competitions. J Sci Med Sport 2015;18:13-18.

61. Laux P, Krumm B, Diers M, et al. Recovery-stress balance and injury risk in professional football players: a prospective study. $J$ Sports Sci 2015;33:2140-8.

62. Moreno J, Ramos-Castro J, Rodas G, et al. Individual recovery profiles in basketball players. Span J Psychol 2015;18:E24.

63. Noon MR, James RS, Clarke ND, et al. Perceptions of well-being and physical performance in English elite youth footballers across a season. J Sports Sci 2015;33:2106-15.

64. Shearer DA, Jones RM, Kilduff LP et al. Effects of competition on the sleep patterns of elite rugby union players. Eur J Sport Sci 2015;15:681-6.

65. Souissi M, Abedelmalek S, Bou Dhiba D, et al. Morning caffeine ingestion increases cognitive function and short-term maximal performance in footballer players after partial sleep deprivation. Biol Rhythm Res 2015;46:617-29.

66. Staunton CA, Gordon BA, Edhem Custovic E, et al. Assessment of sleep patterns in elite female basketball athletes throughout a competitive season. J Aus Strength Cond 2015;23:59-62.

67. Thorpe RT, Strudwick AJ, Buchheit M, et al. Monitoring fatigue during the in-season competitive phase in elite soccer players. Int $J$ Sports Physiol Perform 2015;10:958-64.

68. Andrade A, Bevilacqua GG, Coimbra DR, et al. Sleep quality, mood and performance: a study of elite Brazilian volleyball athletes. $J$ Sports Sci Med 2016;15:601-5.

69. Buchheit M, Cholley Y, Lambert P. Psychometric and physiological responses to a preseason competitive camp in the heat with a 6-hour time difference in elite soccer players. Int J Sports Physiol Perform 2016;11:176-81.

70. Dennis J, Dawson B, Heasman J, et al. Sleep patterns and injury occurrence in elite Australian footballers. J Sci Med Sport 2016;19:113-6.

71. Fessi MS, Nouira S, Dellal A, et al. Changes of the psychophysical state and feeling of wellness of professional soccer players during pre-season and in-season periods. Res Sports Med 2016;24:375-86

72. Fowler PM, Duffield R, Lu D, et al. Effects of long-haul transmeridian travel on subjective jet-lag and self-reported sleep and upper respiratory symptoms in professional rugby league players. Int J Sports Physiol Perform 2016;11:876-84.

73. Fullagar HHK, Skorski S, Duffield R, et al. Impaired sleep and recovery after night matches in elite football players. $J$ Sports $\mathrm{Sci}$ 2016;34:1333-9.

74. Fullagar $\mathrm{H}$, Skorski S, Duffield R, et al. The effect of an acute sleep hygiene strategy following a late-night soccer match on recovery of players. Chronobiol Int 2016;33:490-505.

75. Fullagar HHK, Duffield R, Skorski S, et al. Sleep, travel, and recovery responses of national footballers during and after long-haul international air travel. Int J Sports Physiol Perform 2016;11:86-95. 
76. Gallo TF, Cormack SJ, Gabbett TJ, et al. Pre-training perceived wellness impacts training output in Australian football players. $J$ Sports Sci 2016;34:1445-51.

77. Gouttebarge V, Aoki H, Ekstrand J, et al. Are severe musculoskeletal injuries associated with symptoms of common mental disorders among male European professional footballers? Knee Surg Sports Traumatol Arthrosc 2016;24:3934-42.

78. Gouttebarge V, Aoki H, Verhagen EALM, et al. A 12-month prospective cohort study of symptoms of common mental disorders among European professional footballers. Clin J Sport Med 2017;27:487-92.

79. Gouttebarge V, Tol JL, Kerkhoffs GMMJ. Epidemiology of symptoms of common mental disorders among elite Gaelic athletes: a prospective cohort study. Phys Sportsmed 2016;44:283-9.

80. Caia J, Scott TJ, Halson SL, et al. Do players and staff sleep more during the pre- or competitive season of elite rugby league? Eur $J$ Sport Sci 2017;17:964-72.

81. Fowler PM, Paul DJ, Tomazoli G, et al. Evidence of sub-optimal sleep in adolescent Middle Eastern academy soccer players which is exacerbated by sleep intermission proximal to dawn. Eur J Sport Sci 2017; 17:1110-8.

82. Fowler PM, McCall A, Jones M, et al. Effects of long-haul transmeridian travel on player preparedness: case study of a national team at the 2014 FIFA World Cup. J Sci Med Sport 2017;20:322-7.

83. Fuller KL, Juliff L, Gore CJ, et al. Software thresholds alter the bias of actigraphy for monitoring sleep in team-sport athletes. J Sci Med Sport 2017;20:756-60.

84. Gouttebarge V, Johnson U, Rochcongar P, et al. Symptoms of common mental disorders among professional football referees: a one-season prospective study across Europe. Phys Sportsmed 2017;45:11-16.

85. Ihsan M, Tan F, Sahrom S, et al. Pre-game perceived wellness highly associates with match running performances during an international field hockey tournament. Eur J Sport Sci 2017;17:593-602.

86. Jones MJ, Peeling P, Dawson B, et al. Evening electronic device use: the effects on alertness, sleep and next-day physical performance in athletes. J Sports Sci 2018;36:162-70.

87. Kiliç Ö., Aoki H, Goedhart E, et al. Severe musculoskeletal time-loss injuries and symptoms of common mental disorders in professional soccer: a longitudinal analysis of 12-month follow-up data. Knee Surg Sports Traumatol Arthrosc 2018;26:946-54.

88. Kim JH, Hollowed C, Irwin-Weyant M, et al. Sleep-disordered breathing and cardiovascular correlates in college football players. Am J Cardiol 2017;120:1410-5.

89. CX L, YD W, Wang X. Sleep characteristics of elite blind soccer players in China. Biol Rhythm Res 2017;48:57-64.

90. O'Donnell S, Driller MW. Sleep-hygiene education improves sleep indices in elite female athletes. Int J Exerc Sci 2017;10:522-30.

91. Van Ryswyk E, Weeks R, Bandick L, et al. A novel sleep optimisation programme to improve athletes' well-being and performance. Eur J Sport Sci 2017;17:144-51.

92. Staunton C, Gordon B, Custovic E, et al. Sleep patterns and match performance in elite Australian basketball athletes. J Sci Med Sport 2017;20:786-9.

93. Thorpe RT, Strudwick AJ, Buchheit M, et al. The influence of changes in acute training load on daily sensitivity of morningmeasured fatigue variables in elite soccer players. Int $J$ Sports Physiol Perform 2017;12(Suppl 2):S2-107-113.

94. Tsunoda K, Mutsuzaki H, Hotta K, et al. Correlation between sleep and psychological mood states in female wheelchair basketball players on a Japanese national team. J Phys Ther Sci 2017;29:1497-501.

95. Tuomilehto $\mathrm{H}$, Vuorinen V-P, Penttilä E, et al. Sleep of professional athletes: underexploited potential to improve health and performance. J Sports Sci 2017;35:704-10.

96. Whitworth-Turner C, Di Michele R, Muir I, et al. A shower before bedtime may improve the sleep onset latency of youth soccer players. Eur J Sport Sci 2017;17:1119-28.

97. George Cet al. Sleep and breathing in professional football players. Sleep Med 2003;4:317-25.

98. Bahnert A, Norton K, Lock P. Association between post-game recovery protocols, physical and perceived recovery, and performance in elite Australian Football League players. J Sci Med Sport 2013;16:151-6.
99. Fowler P, Duffield R, Vaile J. Effects of domestic air travel on technical and tactical performance and recovery in soccer. Int $J$ Sports Physiol Perform 2014;9:378-86.

100. Dobrosielski DA, Nichols D, Ford J, et al. Estimating the prevalence of sleep-disordered breathing among collegiate football players. Respir Care 2016;61:1144-50.

101. Eagles AN, Lovell DI. Changes in sleep quantity and efficiency in professional rugby union players during home-based training and match play. J Sports Med Phys Fitness 2016;56:565-71.

102. Pitchford NW, Robertson SJ, Sargent C. A change in training environment alters sleep quality but not quantity in elite Australian Rules football players. Int J Sports Physiol Perform 2017;12:75-80.

103. Hooper SL, Mackinnon LT. Monitoring overtraining in athletes. Recommendations. Sports Med 1995;20:321-7.

104. Hooper SUEL, Mackinnon LT, Howard ALF, et al. Markers for monitoring overtraining and recovery. Med Sci Sports Exerc 1995;27:106-12.

105. Sadeh A. The role and validity of actigraphy in sleep medicine: an update. Sleep Med Rev 2011;15:259-67.

106. Martoni M, Bayon V, Elbaz M, et al. Using actigraphy versus polysomnography in the clinical assessment of chronic insomnia (retrospective analysis of 27 patients). Presse Med 2012;41:e95-e100.

107. Bertolazi AN, Fagondes SC, Hoff LS, et al. Validation of the Brazilian Portuguese version of the Pittsburgh sleep quality index. Sleep Med 2011:12:70-5.

108. Wilkinson K, Shapiro C. Development and validation of the Nonrestorative Sleep Scale (NRSS). J Clin Sleep Med 2013;9:929-37.

109. Van de Water ATM, Holmes A, Hurley DA. Objective measurements of sleep for non-laboratory settings as alternatives to polysomnography-a systematic review. J Sleep Res 2011;20:183-200.

110. Leeder J, Glaister M, Pizzoferro K, et al. Sleep duration and quality in elite athletes measured using wristwatch actigraphy. J Sports Sci 2012;30:541-5.

111. Penzel T. Home sleep testing. In: Kryger M, Roth T, Dement WC, eds. Principles and practice of sleep medicine. 6th edn. Elsevier, 2017-4.

112. Stone KL, Ancoli-Israel S. Actigraphy. In: Kryger M, Roth T, Dement WC, eds. Principles and practice of sleep medicine. 6th edn. Elsevier, 2017: 1610-4.

113. Juliff L, Peiffer JJ, Halson S. Night games and sleep: physiological, neuroendocrine, and psychometric mechanisms. Int J Sports Physiol Perform 2018;13:867-73.

114. Roberts SSH, Teo WP, Warmington SA. Effects of training and competition on the sleep of elite athletes: a systematic review and meta-analysis. Br J Sports Med 2018;Sep 14.

115. Reed DL, Sacco WP. American Academy of Sleep MedicineMeasuring sleep efficiency: what should the denominator be? J Clin Sleep Med 2016;12:263-6.

116. Samuels C, James L, Lawson D, et al. The Athlete Sleep Screening Questionnaire: a new tool for assessing and managing sleep in elite athletes. Br J Sports Med 2016;50:418-22.

117. Carney CE, Buysse DJ, Ancoli-Israel S, et al. The consensus sleep diary: standardizing prospective sleep self-monitoring. Sleep 2012;35:287-302.

118. Marino M, Li Y, Rueschman MN, et al. Measuring sleep: accuracy, sensitivity, and specificity of wrist actigraphy compared to polysomnography. Sleep 2013;36:1747-55

119. A. Barone D, C. Krieger A. The function of sleep. AIMS Neurosci 2015;2:71-90.

120. Grandner MA, Kripke DF. Self-reported sleep complaints with long and short sleep: a nationally representative sample. Psychosom Med 2004:66:239-41.

121. Aeschbach D, Cajochen $\mathrm{C}$, Landolt $\mathrm{H}$, et al. Homeostatic sleep regulation in habitual short sleepers and long sleepers. Am J Physiol 1996;270:R41-53.

122. Aeschbach $\mathrm{D}$, Sher $\mathrm{L}$, Postolache $T T$, et al. A longer biological night in long sleepers than in short sleepers. J Clin Endocrinol Metab 2003;88:26-30.

123. Zavada A, Gordijn MC, Beersma DG, et al. Comparison of the munich chronotype questionnaire with the horne-ostberg's morningness-eveningness score. Chronobiol Int 2005;22:267-78.

124. Roden L, Rudner T, Rae D. Impact of chronotype on athletic performance: current perspectives. Chronophysiol Ther 2017;7:1-6. 